\title{
Greater awareness of security in aftermath of computer worm
}

\section{Boston \& Washington}

LIKE residents shellshocked after a spate of break-ins in their neighbourhood, computer network users at universities and research institutions around the United States agree that they have been forced into greater awareness of security issues by the recent attack of an unauthorized computer program upon thousands of computer systems around the country using the ARPANET, Milnet and NSF Net computer networks (see Nature 336, $97 ; 1988)$. The debate has now begun over whether increased security is needed in computer networks, and, if that is the case, how that will affect the free exchange of information.

If nothing else, the computer virus - or worm - that infected computers using a version of the UNIX operating system drove home how much computer networks have become part of the social structure of conducting science. Although the damage caused by the worm was slight, requiring no more than a fairly simple patch to electronic mail and related software source codes, most systems were removed from the networks for days while the repairs were made.

On electronic bulletin boards, the debate raged over whether Robert $T$. Morris, the Cornell University graduate student alleged to have come up with the invader was a 'hacker hero' or a criminal. Some believe that Morris uncovered significant flaws in the UNIX mail system, although others claim the flaws were wellknown, and it was irresponsible to exploit them.

Users of the network seem to realize that it is not possible to construct a bugproof system. Most suggestions for coping with future invasions involved raising the ethical standards of users, and simple but effective counter-measures such as requiring users to change their passwords frequently, and to use nonsense or random characters as passwords so that they cannot be easily deduced by clever programs.

James D. Bruce, professor of electrical engineering at Massachusetts Institute of Technology (MIT) and vice-president for Information Systems, says that several analysts and observers have begun to discuss tightening access to computer networks and even the possibility of closing down some of the networks. "Many people are hailing this as the end of the userfriendly era of computing, but if we've gone that far we have literally put our heads in the sand, or locked ourselves into a fortress we can't get out of", he says.

Last week in Washington, computer security experts from the Department of Defense and the National Security
Agency as well as other government agencies met to discuss what changes in network policy might be needed on a national level, but they have not yet released the results of their deliberations.

Bruce also says that teams at MIT have begun to look for programs that can be deleted from MIT networks. The ARPANET computer worm used a debugging program left on several versions of the 'sendmail' program on the Unix operating system to enter new computer systems. MIT's Project Athena computer network had already deleted this program from their version of "sendmail" and thus was largely spared from the virus attack. Bruce also stresses that his network managers are considering limiting access to certain programs to those with appropriate priority.

Despite these efforts, many researchers agree that the risks of attack through the networks are still significant. According to

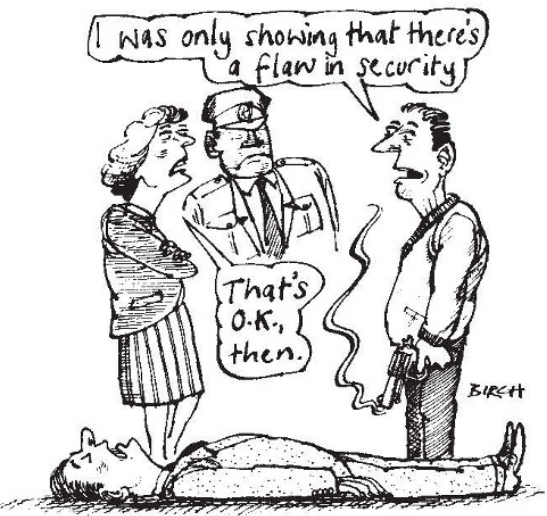

Pascal Chesnais, research specialist at the MIT Media Laboratory and the user first to discover the worm at MIT, "It used to be that an isolated group was using the networks. They didn't need any passwords; there were no abuses. But things have changed." Chesnais likens the situation to people's homes, saying that people put locks on their front doors "mainly as a deterrent". If that proves insufficient, he says, "people begin to install alarm systems". Eventually, he says, it can get to the point where it is difficult to get into one's own home. Then, "you've clearly gone too far. Unfortunately, I'm afraid computer networks may get to be that way."

The Federal Bureau of Investigation (FBI) is investigating the worm attack to see if there were any violations of the Computer Fraud and Abuse Act of 1986. Last week, the FBI obtained search warrants for computer tapes with Cornell University containing "files from the Morris account including backups".

Seth Shulman \& Joseph Palca

\section{Mathematics and molecular biology}

THE time is ripe for mathematics to make an impact on molecular biology, say the organizers of a University of California (UC) programme aimed at facilitating interaction between the two fields. The Program in Mathematics and Molecular Biology, based at the University of California at Berkeley, has received a \$2-million, five-year grant from the National Science Foundation to suppport collaborative research projects, fellowships and research conferences and workshops.

Although the programme is based at Berkeley, nine of the first eleven research projects it will support are scattered at different institutions around the United States. The projects focus on areas including DNA geometry and topology, proteinfolding and genome mapping.

Sylvia Spengler, a biophysicist at the Lawrence Berkeley Laboratory and academic administrator for the programme, says that directions for future research will be evaluated with the aid of a five-member advisory board, which includes Genentech's vice-president for science, David Botstein, and biophysicist Aaron Klug of Britain's Medical Research Council.

The idea for the endeavour grew out of a collaborative study involving mathematical analysis of the geometry of DNA by Spengler, her biology colleague Nicholas Cozzarelli at Berkeley, and mathematicians Vaughan Jones at Berkeley, James White of the University of California, Los Angeles, and DeWitt Sumners at Florida State University.

Spengler and Cozzarelli realized that many areas of molecular biology could benefit from mathematics, but that collaborations might be slow to start because mathematicians and biologists are unfamiliar with work in each others' fields.

The programme was thus designed to act as a 'broker', said Spengler, and bring mathematicians and biologists together. At its Berkeley home base, it will keep several offices for visiting scholars who are likely to benefit from interactions with the Berkeley Center for Pure and Applied Mathematics and the Mathematical Sciences Research Institute.

Although the programme will be supporting relatively few researchers at any one time, Spengler said its research conferences and workshops will catalyse interactions among a broader circle of researchers. The first conference, planned for 1989 in Florida, will deal with applications of topology and geometry to molecular biology. Spengler hopes eventually to extend the programme's influence to European scientists by sponsoring joint workshops in conjunction with the NATO Research Series.
Marcia Barinaga 